\title{
TEACHING MATHEMATICS THROUGH ONLINE COLLABORATIVE ENVIRONMENT IN THE HIGHER EDUCATION CONTEXT
}

\author{
Bushra Al Kalbani ${ }^{*}$, Vikas Rao Naidu ${ }^{2^{*}}$, Rajani Rani Gupta ${ }^{3}$, Azahir Al Sawafi ${ }^{4}$ \\ ${ }^{1}$ Ms, Middle East College, Muscat Oman, balkalbani@mec.edu.om \\ ${ }^{2} \mathrm{Mr}$, Middle East College, Muscat Oman, vikas@mec.edu.om \\ ${ }^{3} \mathrm{Ms}$, Middle East College, Muscat Oman, rajani@mec.edu.om \\ ${ }^{4}$ Ms, Middle East College, Muscat Oman,18f18086@mec.edu.om \\ ${ }^{*}$ Corresponding authors
}

\begin{abstract}
The higher education sector is continuously working towards the improvement of support mechanism by means of strengthening of education technology and various other strategies. This requirement differs from the nature of the subject. For technical subjects, it is much easier to take the assistance of technology, such as online tools, videos, animation, interactive applications and much more. Whereas, subjects like Mathematics and Language learning, has a totally different scenario. However, the higher educational institutions are adopting a various innovative approach to enhance the student learning experience. This research paper focuses on some of those methods, which are adopted to improve Mathematics education at the foundation level in one of the higher educational institution in the Sultanate of Oman. The foundation level education was introduced to bridge a gap of basic requirements, which some of the students lack while completing their higher school and takes admission in the diploma or bachelor studies. Foundation Mathematics is one of the subjects which is being taught at this level. Although, there is a provision that student can opt for clearing a challenge exam and get admitted to the first semester, still many of the students opt for studying foundation due to various factors. In their school education, they are not allowed to use smartphones or devices during their classes. Whereas, in college, they can use their devices for educational purposes. The module leader prepares a session plan according to the learning outcomes and maps various activities with the support of various tools. Some of these tools are online, which are accessible on mobile phones. One such useful tool is Kaizala, which allows students to collaborate with each other to participate in various activities being conducted by the faculty members. It supports almost all the multimedia content such as audio, video, animation, interactive quizzes, polling, sharing of images, etc. In this research paper, the authors have described the implementation of such collaborative tools in various ways, to enhance student understanding. Finally, the method was found to be very useful and it has improved the results. Part-time students also found it quite useful, as they were able to participate in the class activities even if they are unable to make-up to some of their classes due to some official reasons. There were students who were repeating the subject for more than one time and who have also found such methods as quite useful ones. Overall, the experience of introducing online collaborative tools to improve the learning mechanism of Mathematics related subject was found to be very good.
\end{abstract}

Keywords: Smart education for Mathematics, e-resources, online collaborative learning, education technology, social media for education

\section{INTRODUCTION}

Mathematics teaching has always faced certain challenges with respect to the attention span of all the 
participating students in most of the classes. Many students find it interesting and they even excel in the subject, however, many struggles to learn either due to lack of lack of interest or due to lack in motivation. These days in many higher educational institutions, the concept of flipped classroom has been deployed where students are provided with learning materials in advance. These could be in the form of videos and later during their class sessions, various interactive activities are conducted, such as quizzes, puzzles etc. (Bhatia and Naidu, 2016). During past few years, to overcome the limitations of the traditional way, various researches attempted to examine the use of technologies into the teaching and learning process in the higher education. Tsvetozar Georgiev, Evgenia Georgieva, Angel Smrikarov (2004) discussed the existing devices and technologies that can be used to initiate mobile learning as new stage of the progress of distance learning and e-Learning. They have also presented the advantages of using mobile learning devices over the e-learning. They concluded that the assimilation of technologies will make the education process more flexible and will fulfil the needs of life-long learning. Nadire Cavus and Dogan Ibrahim (2008) examined the impact and usage of wireless technologies in learning new technical English language words by means of Short Message Service (SMS) of text messaging and found that a noticeable improvement in the students' performances.

Some of the researchers conducted surveys (on students and instructors) in their countries (of their work) and conclude that the students and instructors have positive insights of mobile learning (Yusri, Goodwin and Mooney (2015), Hunaiyyanm Alhajri and Al-Sharhan (2018)). Their study depicts that the mobility, flexibility, ubiquity, ease of access, improved communication between the leaners and facilitators is very much appreciated. They found that the financial and devices used were not obstacles in the path of their collaborative learning. They found that the faculties who teach social sciences (mathematics, science, and other subjects) and more interested and involved as compared to those who teach ICT subjects. Their study helped them in designing and developing the mobile learning system for their institutes. It was also reported that this learning has some social and cultural barriers. Especially when it comes to usage of social media platforms for conducting activities related to teaching and learning, various online collaborative tools need to be reviewed for implications from various aspects. These aspects involve various social and legal consideration. (Al Mamari, Naidu and Agarwal, 2019) Many students have some reservations when they are provided with option to participate in collaborative environment and to interact with fellow colleagues or peers. Hence, it is important to formulate a working environment, that facilitates increased level of student participation, as they do not have to share their personal contact information.

\section{REVIEW OF EXISTING SYSTEM}

The study was conducted based on implementation of this idea on a focused group chosen from one of the leading Higher Education Institutions ( $\mathrm{HEI}$ ), in Oman. All the participants have taken part by providing their consent. In most of the HEls, the students are required to undergo one-year foundation study before they enter semester 1 . This is because, the students should possess the knowledge of the basic skills before starting their under-graduate studies. Generally, students get acquainted with these skills at their high secondary school level. In case a student is not able to demonstrate the knowledge of required basic skills, most of the educational institutes allow them to equip this at the General Foundation Program (GFP). GFP program enables students to learn, practice, and gain competence mainly in four basic skills, viz, English, mathematics, IT and Study skills which make the fundamental of any undergraduate degree. This program not only facilitates students with these skills but also supports them to develop communication and teamwork skills. In this paper, we have analysed the performance of the students taking GFP mathematics modules in one of the HEl in Oman. In general, at any GFP, three-level of mathematics modules are taught, namely General Mathematics (which include the basics of arithmetic operations), Pure Mathematics (meant for students undertaking engineering programmes) and Applied Mathematics (for the students seeking to have a carrier in the business and management studies related programmes).

This study is conducted for the Spring semester during 2019. Out of 345 students that registered in the GFP program, there were 71 students who were repeating the module several times. At the beginning of the semester, numerous extra classes/peer tutoring sessions/ workshops have been arranged for all GFP students to support their learning and in-turn to enhance their performance in these modules. The aim of these sessions is also to improve the overall performance of the GFP programme. These sessions were conducted on a weekly basis (twice each week) for all three modules so that the students will have a chance to attend at least one of the sessions. The students were informed in advance about these sessions by various means, emails, verbal communication by their instructors during their normal class, etc. Although many efforts have been put together to increase student attendance and participation in these classes, only a few students turned up for the sessions. When we investigated for the reasons of low attendance, we found that "having another session at the same time", "transportation issue", "continuous classes during the 
day", "some other personal engagement at the time of the session", are some of them to mention. The unproductiveness of our effort directed us to look for a technique/method to get in contact with such students outside the campus, even after the class contact hours and as per their convenience.

Authors were already acquainted with the knowledge of using the WhatsApp application for education purpose, by forming student groups (that include all students of a session) and using it to discuss the difficulties faced by the students in the module (Gupta, Liago, and Gupta 2017). One of the limitations of the WhatsApp is that student must share their contact details to be a member of the group, which is visible to all the other participants. It is noticed that most of the students are not participating in such study groups as well. After investigation, it is found that not all the students (especially female students) are comfortable sharing their personal contact information with everyone, which is the necessity of a WhatsApp group. So, we explored for an application having similar features to that of WhatsApp, but more secluded, without the requirement of sharing the personal contact information. The purpose of having an application like WhatsApp as mentioned above is due to its user-friendly interface and compatibility. This will make students learn effortlessly and hence will increase their participation in the activities.

The recent trends in education technology has also involved various plugins of learning analytics and machine learning along with online platforms. This facilitates prediction of results of the participating students based on their present performances and the faculty can take necessary measures to improve the results in future by various methods to make students understand that specific topic clearly, once again. Simple dashboard can be further helpful to have a big picture of the entire cohort and their performances. (Rao Naidu et al., 2017) (Naidu et al., 2020)

\section{METHODOLOGY}

Most of the students are unable to attend the extra classes/ peer-tutoring classes because of their class timings, transportation, and any other personal issues. This resulted in dropping down their performance in the module. Dean (2008) explored the integration of non-traditional activities to enhance the learning of mathematical concepts. He used hands-on activities, written explanations, and oral communication, which demand a new mathematical concept that help students to relate a new mathematical concept with their prior knowledge or a real-world application. This activity helped him to reach a diver's learners of his class. He found that assimilating such activities have not only increased the abilities to use mathematical knowledge of his students to different applications, but also helped then to improve their communication skills. In view of his work, we planned to use a mobile application Kaizala from Microsoft as a non-traditional way of teaching, which will provide enough time to our students to think and in turn will increase their abilities to solve problems. We have included some small video explanations with mathematical reasoning for the better understanding of the students.

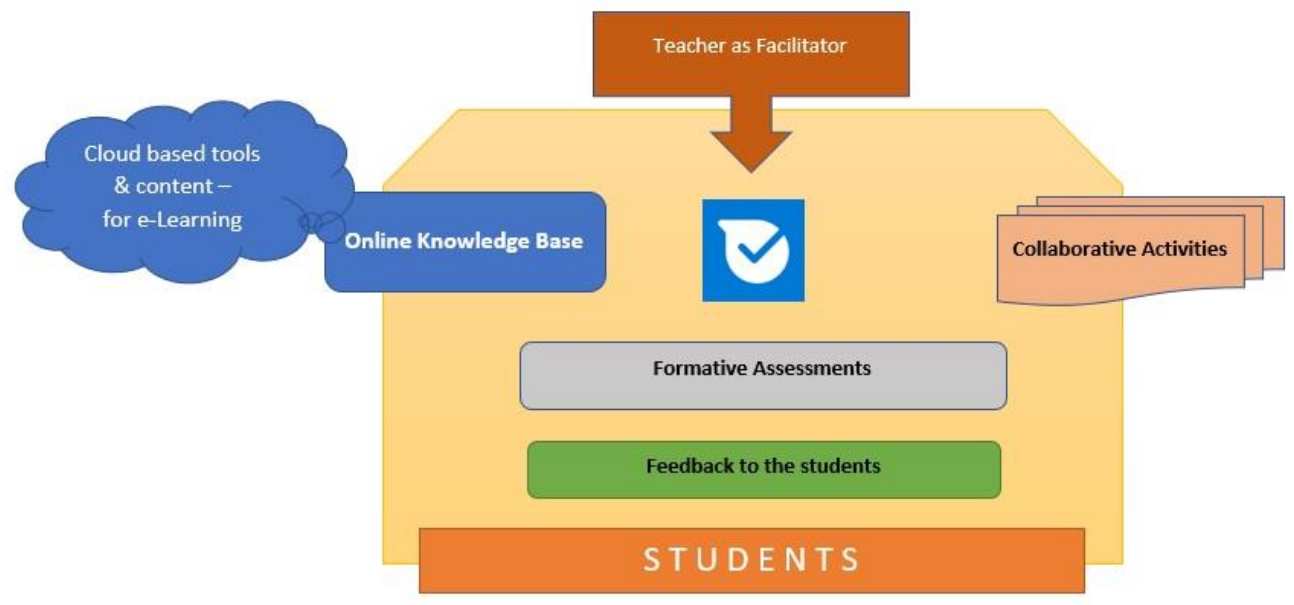

Figure 1. Methodology followed in this Approach

Here the teacher acts as a facilitator of the entire teaching process where he/she opens the session on collaborative tool such as Kaizala, a tool like WhatsApp. Various other tools and content for e-Learning could be taken from the cloud such as e-books, presentations, research article, etc as reference materials. There are some authoring tools for e-content development which could be used by the teachers to prepare the content on cloud and share with the students on social media platform.

Collaborative activities are planned to ensure that whatever content is prepared by the teacher / peers could 
be easily shared. The following section shows implementation of one such activity where students have solved mathematics problem on the paper and shared the photo of the same in Kaizala group.

Other stages involved, conduct of formative assessments and providing instant feedback to the students in the group. This feedback could be given by either teacher or the peers.

While we plan to implement these techniques, it is important to organize regular orientation sessions for the staff as well as students, preferably at the beginning of the semester. (Mohammed and Naidu, 2018) This is especially for those, who have never used online collaborative environment in teaching and learning process.

\subsection{Application Used for Collaborative Activities in Classroom - Microsoft Kaizala:}

Microsoft Kaizala is a social media networking application which is like any other social media applications like, WhatsApp in use but is more aided. This application support Math keyboards which support and improve the students' performance and communications skills. The advantage of using Kaizala is that with this application students can collaborate with the facilitator or other students anytime and anywhere by giving them training, quiz, survey and poll. (Microsoft Kaizala - Office 365 2016). One additional benfirt of using Kaizala over Whatsapp is that here students need not to share their contact number to be member of the group. This will overcome the social and cultural barriers as investigated by other researches as well in their work (Hunaiyyanm Alhajri and Al-Sharhan (2018)). They can become member by just registring through a link or by a QR code.

The following are some of Kiazala's features:

- Training- This tool provides option of sending videos/text/ study material followed by a quiz to test their understanding. It is also used for flipped learning.

- Quiz-this tool allows conducting a quiz after a lesson is finished.

- Survey- this is used to conduct the survey.

- Games- there are some good and creative games which can be played for brainstorming.

- Poll-this allows to conduct polls to gather feedback from students.

- Teacher can immediately clear doubts of students. More exercises can be given and can be corrected by using voice or image.

- Online videos including videos developed by the teacher videos can be easily shared among the students.

\subsection{Other Applications available for similar purpose:}

There are many other online applications which are available for similar purpose. Such as Padlet, Whatsapp, LiveBoard etc. But Kaizala has its own advantages due to rich number of embedded features. Unlike Kaizala, it's not possible to conduct online poll, on other mobile apps mentioned above. Online poll or even activities such as quizzes are important for academic purpose apart from team communication. The only advantage of LiveBoard app over Kaizala is, it functions even without internet connection. The group members can connect to a shared page with teacher through hotspot option (WiFi) of the host device. Many free and open source applications are also available to customize and implement for various e-learning purposes (Naidu, Singh, Al Harrasi, \& Al Balushi, 2017). Not only this, there are some game based applications which can be customized for collaborative activities among the students especially as brainstorming exercises (Naidu, Balushi, \& Bhatia., 2017).

\section{IMPLEMENTATION}

A group was created in Kaizala. A link was shared to the group. Students were instructed on the advantages and procedures in using this app. At the initial stage, these online classes were conducted by the one instructor only. After observing valuable impact of these classes, and its results in improving the pass percentage of the students, these groups were extended to the peer tutoring students and the other module instructors. A raise in the number of students was observed in these groups as compared to their numbers at the beginning. Also, some of the repeater students have improved their performances. This also helped and trained the peer tutors to become more confident in conducting workshops and activities. Due to use of this online application, the number of students approaching to the faculties during the office hours is reduced. This application helped students to work collaboratively in group and learning from each other through their active participation group discussion. 
Students in the group responded with various solutions by solving them in their notebooks and by sharing the images of those solution in the group. These solutions were then checked by either the peers or the faculty and necessary response were posted in the group with proper comments and feedback. Some activities also involved sharing of videos for problem solving, quick poll, etc. as shown in the figure below.

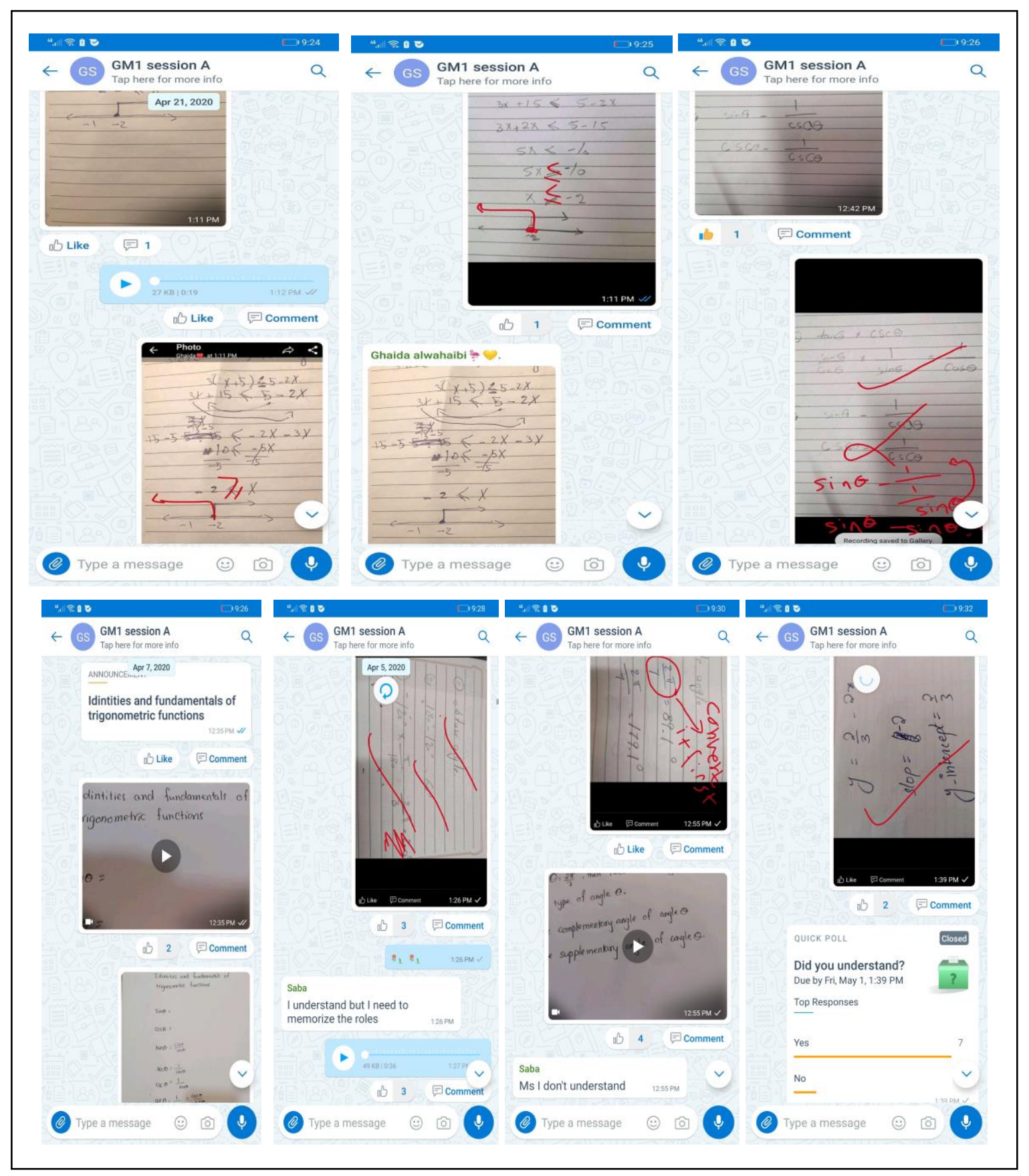

Figure 2. Solution to a problem shared by a student on Kaizala group

They will be motivated by the whole process. In some cases, diligent students are even motivated to ask more questions for practice. Figure 1 shows an image shared by one of the group members in Kaizala, which he has shared the solution to a problem and received immediate feedback if its correct.

\section{RESULTS}

Kaizala messenger provide the ability for students to send messages almost without limits. Students use Kaizala through a variety of mobile devices, such as smartphones or tablets and can message one another through texts, images, voice notes, and videos. Kaizala has a good and attractive user interface and students are already comfortable using the application as it has same interface as WhatsApp. 


\subsection{Effectiveness}

In our classes, using Kaizala proved very helpful in encouraging students to practice and solve exercises at home. Immediate feedback combined with motivating students to work and attempt exercises outside the class makes for better student learning. After involving Alumni and peer tutor students, this become more effective. Students actively participated in solving questions at their homes at their own pace and once they get stuck/confused, ultimately, they'll stop practicing. But through this innovation, they can put their question (or the point where they get stuck) in the Kaizala. Studies shows that if one gets immediate feedback on their work, the person will be more productive and motivated (Hattie, J. and Timperley, H. (2007), AITSL (2017)). In the group, another student may know the solution and will help out. The role of instructor comes once they all are not able to answer. This app helped students post their problems and they'll get their solution.

\subsection{Assessments and final outcomes}

It was found out that this method is helpful in improving communication with students. After involving Alumni and peer tutor students, this becomes more effective. Lectures were conducted by recording videos, training the students and giving them quizzes online. This method shall serve as additional resources to students especially those in SWOM (Students Working outside Muscat city) category.

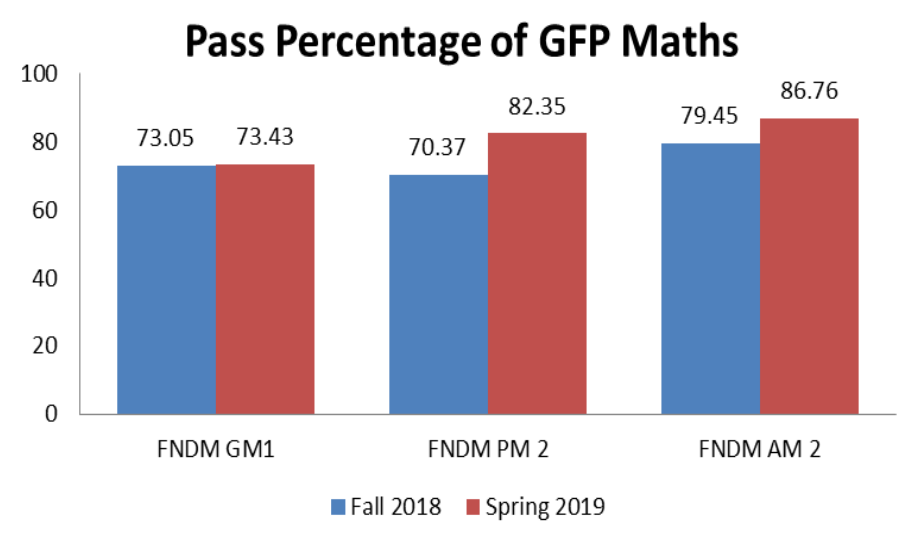

Figure 3. Comparison of results before (Fall 2018) and after (Spring 2019) using the Kaizala application

Through this method, students' mathematical abilities will be enhanced and more motivated and interested in learning Maths. The results showing the comparison between the semesters Fall 2018 (without using Kaizala) and Spring 2019 (using Kaizala) is shown in figure 2.

\subsection{Feedback}

Feedback was collected from the students who were involved in the learning through this application. Methods used in collecting feedback were both quantitative as well as qualitative. Majority of students have found the application excellent, and easy to use.

What is the benefit of using Kaizala app in your studies?
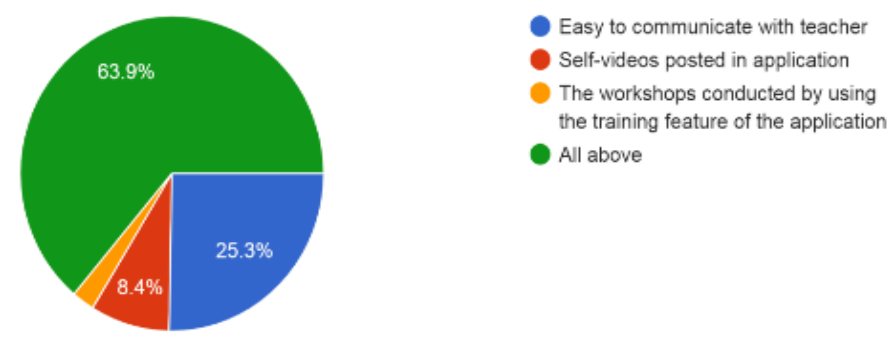

Figure 4. Feedback from the Alumni, peer-tutors and current students 
As we see in Figure 4, majority of the respondents have given their response in favour of usage of Kaizala as their preferred tool for conducting collaborative classroom activity. They have identified that Kaizala is easy to communicate with the teacher.

Other feedback which was taken from the participants were in the form of open-ended question. Majority of them are very impressed by the way the activities were organized and conducted in the group. The students found this way of collaborative learning very useful, as they can learn from alternative solutions to the same problem.

This also gives chance to explore more by the students and the video-based solutions with voice over simulates an environment of real time learning, even if the students are unable to attend the class due to some unavoidable circumstances. This method was highly effective even for the students working outside the city and who are unable to attend the classes regularly.

Further, it gave an opportunity for peer tutors to share their knowledge with the group of students in a fast and easy way, and they got instant feedback from the participants.

\section{CONCLUSION}

The method used by implementing Kaizala was found to be very effective and fruitful. Students' performance has increased as compared to previous semesters and now the important topics of discussions are easily accessible even from a remote location. Even if a student is missing any class due to any reason, they can still go through the activities that have taken place on that day through the group. Sometimes, students were coming up with alternate solutions to the problems, which they have shared in the group. And hence this gave multiple ways to solve one mathematical problem by the student, and the student had option to choose from different methods. Overall, response of the students was very positive. Moreover, the intermediate collected through blitz feedback has shown a very positive feedback from the students.

\section{ACKNOWLEDGEMENT}

The authors would like to sincerely thank God almighty whose blessings were there in each stage of successful completion of this collaborative research work. Authors would thank the faculty and management of Middle East College for encouragement in this research. Our sincere thanks to our families who are always encouraging us in new ventures towards our academic success.

\section{REFERENCE LIST}

Bhatia, S. and Naidu, V. R. (2016) 'FLIPPED TEACHING IN MATHEMATICS', (July), pp. 8627-8632.

Al Mamari, R., Naidu, V. R. and Agarwal, A. (2019) 'A PROPOSED FRAMEWORK FOR EFFECTIVE USAGE OF SOCIAL MEDIA IN HIGHER EDUCATION ESTABLISHMENTS', in EDULEARN19 Proceedings. IATED, pp. 7337-7341. doi: 10.21125/edulearn.2019.1755.

Mohammed, Q. A. and Naidu, V. R. (2018) (PDF) USING SOCIAL MEDIA AS A COLLABORATIVE TOOL FOR ENHANCED LEARNING IN HIGHER EDUCATION, Oxford Conference Series, FLE Learning, UK. Available at: https://www.researchgate.net/publication/342612183_USING_SOCIAL_MEDIA_AS_A_COLLABORA TIVE_TOOL_FOR_ENHANCED_LEARNING_IN_HIGHER_EDUCATION (Accessed: $\overline{5}$ July 2020).

Naidu, V. R. et al. (2020) 'Machine Learning for Flipped Teaching in Higher Education-A Reflection', in. Springer, Cham, pp. 129-132. doi: 10.1007/978-3-030-32902-0_16.

Rao Naidu, V. et al. (2017) LEARNING ANALYTICS FOR SMART CLASSROOM IN HIGHER EDUCATION. Ocerint International, Istanbul. Available at: http://www.ocerint.org/socioint17 epublication/abstracts/papers/432.pdf (Accessed: 1 June 2020).

Georgiev, Evgenia Georgieva, Angel Smrikarov (2004), M-Learning - a New Stage of §-Learning, International Conference on Computer Systems and Technologies - CompSysTech-2004.

Nadire Cavus and Dogan Ibrahim (2008), m-Learning: An experiment in using SMS to support learning new English language words, British Journal of Educational Technology 40(1):78 - 91 .

Virvou, M. and Alepis, E. (2005), Mobile educational features in authoring tools for personalized tutoring. Computing and Education, 44, 53-68. 
Uzunboylu, H., Cavus, N, and Ercag. E. (2009), Using mobile learning to increase environmental awareness. Computer and Education, 52(2), 381-389.

Presnsky, M. (2007), How to teach with technology: keeping both teachers and students comfortable in an era of exponential change. Emerging Technologies for learning, 2, 40-46, Retrieved August 2012 from http://partners.becta.org.uk/page_documnets/reseacrh/emerging_technologies07_chapter4.pdf.

Mallikikharjuna, N., Sasidhar, C. and Satyendra, V. (2010), Cloud computing through mobile learning, International journal of Advanced computer science and applications (IJACSA), 1, 6.

Sarrab, M. and Elgamel, L. (2013), Contextual M-learning system for higher education providers in Oman, World Applied Sciences Journal, 22, 10, 1412-1419.

Samsiah Bidin and Azidah Abu Ziden (2013), Adoption and application of mobile learning in the education industry, 6th international conference on university learning and teaching (InCULT2012), ProcediaSocial and Behavioural Sciences, 90, 720-729.

Mohammed T, Al-Hariri, and Abdulghani A, Al-Hattami (2017), Impact of students' use of technology on their learning acheivemnets in physiology courses at the University of Dammam, Journal of Taibah University Medical Sciences, 12(1), 82-85.

lin Karmila Yusri, Robert Goodwin and Carl Mooney (2015), Teachers and mobile learning perception: towards a conceptual model of mobile learning for training, Procedia-Social and Behavioural Sciences, 176, 425-430.

Ahmed Al-Hunaiyyanm, Rana A. Alhajri and Salah Al-Sharhan (2018), Perceptions and challenges of mobile learning in Kuwait, Journal of King Saud University-Computer and Information Sciences, 30, 279-289.

Cetinkaya, L. (2017) 'The Impact of Whatsapp Use on Success in Education Process', vol. 18, November.

Naidu, V. R., Balushi, H. A., \& Bhatia., S. (2017). Effectiveness Of Free \& Open Source Tools To Enhance Game Based Learning Experience In School Education. International Conference on Education and New Learning Technologies (pp. 6604-6609). Barcelona, Spain: IATED.

Naidu, V. R., Singh, B., Al Harrasi, R. A., \& Al Balushi, H. H. (2017). TECHNOLOGY ENHANCED LEARNING ASSISTED BY FREE AND OPEN SOURCE SOFTWARE. 3(8).

Gupta, R.R., Liago, G.R. and Gupta, R.R. (2017) 'Mobile Messaging Applications As An Educational Tool', Proceedings of INTED2017 Conference, Spain.

AITSL (2017) 'Reframing feedback to improve teaching and learning', pp. 1-15.

Hattie, J. and Timperley, H. (2007) 'The power of feedback. [References]', Review of Educational Research, vol..77, no. 1 , pp. 16-7.

Dean, S. (2008) Using Non-Traditional Activities to Enhance Mathematical Connections.

Microsoft Kaizala - Office 365 (2016), [Online], Available: HYPERLINK

"https://products.office.com/en/business/microsoft-kaizala"

https://products.office.com/en/business/microsoft-kaizala [29 Mar 2019].

Cheong, C. (n.d) 'Designing a Mobile-app-based Collaborative Learning System', Journal of Information Technology Education: Innovations in Practice.

EduTech: The best camera calculator apps for iPhone and iPad - 9to5Mac (2018), [Online], Available: HYPERLINK "https://9to5mac.com/2017/03/05/photo-math-solving-apps-for-ios/" https://9to5mac.com/2017/03/05/photo-math-solving-apps-for-ios/ [29 Mar 2019].

Lopes, I., Oliveira, A. and Costa, C.J. (2015) 'Tools for Online Collaboration: Do they contribute to Improve Teamwork?', Mediterranean Journal of Social Sciences, no. January 2016.

Mohammed, Q., Rao, V., Hassan, R., Mustafa, M. and Jesrani, K. (2019). Digital Education Using Free And Open Source Tools To Enhance Collaborative Learning. [online] ljaedu.ocerintjournals.org. Available at: http://ijaedu.ocerintjournals.org/tr/download/article-file/705009 [Accessed 21 Sep. 2019].

Mustafa, M., Rao, V., Mohammed, Q., Jesrani, K., Hasan, R. and Al Hadrami, G. (2019). A Framework For Collaborative And Activelearning For Enhancing Student Engagement. [online] ljaedu.ocerintjournals.org. Available at: http://ijaedu.ocerintjournals.org/en/download/article-file/705026 [Accessed 12 Sep. 2019]. 